\title{
Z

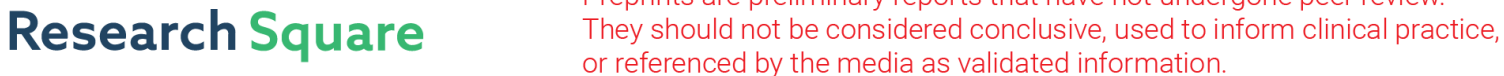

\section{Cell-Free Fat Extract Attenuate Osteoarthritis via Chondrocytes Regeneration and Macrophages Immunomodulation}

\section{zhuoxuan jia}

Shanghai 9th Peoples Hospital Affiliated to Shanghai Jiaotong University School of Medicine

\section{Bijun Kang}

Shanghai 9th Peoples Hospital Affiliated to Shanghai Jiaotong University School of Medicine

\section{Yizuo Cai}

Shanghai 9th Peoples Hospital Affiliated to Shanghai Jiaotong University School of Medicine

\section{Chingyu Chen}

Shanghai 9th Peoples Hospital Affiliated to Shanghai Jiaotong University School of Medicine

\section{Zheyuan Yu}

Shanghai 9th Peoples Hospital Affiliated to Shanghai Jiaotong University School of Medicine

\section{Wei Li ( $\sim$ liweiboshi@163.com )}

Shanghai 9th Peoples Hospital Affiliated to Shanghai Jiaotong University School of Medicine https://orcid.org/0000-0002-2366-0621

\section{Wenjie Zhang}

Shanghai 9th Peoples Hospital Affiliated to Shanghai Jiaotong University School of Medicine

\section{Research Article}

Keywords: Osteoarthritis, Cartilage regeneration, Synovitis, Macrophage

Posted Date: January 12th, 2022

DOI: https://doi.org/10.21203/rs.3.rs-1242320/v1

License: (c) (1) This work is licensed under a Creative Commons Attribution 4.0 International License. Read Full License

Version of Record: A version of this preprint was published at Stem Cell Research \&amp; Therapy on April 1st, 2022. See the published version at https://doi.org/10.1186/s13287-022-02813-3. 


\title{
Cell-Free Fat Extract Attenuate Osteoarthritis via Chondrocytes Regeneration and Macrophages Immunomodulation
}

Zhuoxuan Jia ${ }^{\dagger}$, Bijun Kang ${ }^{\dagger}$, Yizuo Cai, Chingyu Chen, Zheyuan $\mathrm{Yu}^{*}$, Wei Li ${ }^{*}$, and Wenjie Zhang* Department of Plastic and Reconstructive Surgery, Shanghai 9th People's Hospital, Shanghai Jiao Tong University School of Medicine, Shanghai Key Laboratory of Tissue Engineering, National Tissue Engineering Center of China, 639 ZhiZaoJu Road, Shanghai 200011, China

*Correspondence: zheyuan_yu@qq.com (Zheyuan Yu); liweiboshi@163.com (Wei Li); wenjieboshi@aliyun.com (Wenjie Zhang)

${ }^{\dagger}$ Zhuoxuan Jia and Bijun Kang contributed equally to this work.

\begin{abstract}
Background: The prevalence of osteoarthritis (OA) is increasing, yet clinically effective and economical treatments are unavailable. We have previously proposed a cell-free fat extract (CEFFE) containing multiple cytokines, which possessed anti-apoptotic, anti-oxidative, and proliferation promotion functions, as a "cell-free" strategy. In this study, we aimed to evaluate the therapeutic effect of CEFFE in vivo and in vitro.
\end{abstract}

Methods: In vivo study, sodium iodoacetate-induced OA rats were treated with CEFFE by intra-articular injections for 8 weeks. Behavioral experiments were performed every two weeks. Histological analyses, anti-type II collagen, and toluidine staining provided structural evaluation. Macrophage infiltration was assessed by anti-CD68 and anti-CD206 staining. In vitro study, the effect of CEFFE on macrophage polarization and secretory factors was evaluated by flow cytometry, immunofluorescence, and quantitative reverse-transcription polymerase chain reaction (qRT-PCR). The effect of CEFFE on cartilage regeneration was accessed by cell counting kit- 8 assay and qRT-PCR. The generation of reactive oxygen species (ROS) and levels of ROS-related enzymes were investigated by qRT-PCR and western blotting.

Results: In rat models with sodium iodoacetate (MIA)-induced OA, CEFFE increased claw retraction pressure while decreasing bipedal pressure in a dose-depend manner. Moreover, CEFFE promoted cartilage structure restoration and increased the proportion of $\mathrm{CD} 206^{+}$ macrophages in the synovium. In vitro, CEFFE decreased the proportion of $\mathrm{CD} 86^{+}$cells and reduced the expression of pro-inflammatory factors in LPS + IFN- $\gamma$ induced Raw 264.7. In addition, CEFFE decreased the expression of interleukin- 6 and ADAMTs- 5 and promoted the expression of SOX-9 in mouse primary chondrocytes. Besides, CEFFE reduced the intracellular levels of reactive oxygen species in both in vitro models through regulating ROS-related enzymes. 
Conclusions: CEFFE inhibits the progression of OA by promoting cartilage regeneration and limiting low-grade joint inflammation.

\section{Keywords}

Osteoarthritis; Cartilage regeneration; Synovitis; Macrophage

\section{Background}

Osteoarthritis (OA) is a common degenerative disorder characterized by the gradual degradation of articular cartilage, synovial inflammation, and remodeling of the subchondral bone $[1,2]$. The physiological symptoms of OA mainly include pain, joint stiffness, and reduced motion, all of which significantly affect the quality of life of the patient [3-5]. However, current therapies for OA include nonsurgical management (e.g., weight reduction, exercises) and pharmacological interventions such as nonsteroidal anti-inflammatory drugs and paracetamol, which only temporarily alleviate clinical symptoms rather than repairing the tissues lesions or inhibiting the progression of OA [6-8]. Total joint arthroplasty is an effective treatment for the end-stage joint disease; however, the longevity of the prosthetic is limited, and the functional outcomes might be poor $[9,10]$. Hence, in our study, we shifted the focus towards the treatment of early OA [9].

Although the pathological mechanisms are not well elucidated, accumulating evidence has suggested that apoptosis of joint cartilage tissues and the activation of innate inflammatory pathways (synovial macrophages in particular) play a critical role in the development of OA $[11,12]$. Specifically, long-term cartilage degradation results in a release of tissue and molecular fragments as damage-associated molecular patterns that in turn activate synovial macrophages for the removal of these fragments [13]. However, synovial macrophages are over-activated to further damage the cartilage and form a positive feedback [7, 13]. This phenomenon is closely related to the subtypes of macrophages, including the pro-inflammatory M1 or anti-inflammatory M2 states [14]. M1 macrophages secrete many pro-inflammatory cytokines and mediators, such as tumor necrosis factor- $\alpha$ (TNF- $\alpha$ ) and interleukin (IL)- $1 \beta$, that recruit other immune cells to phagocyte cell debris $[15,16]$. In contrast, M2 macrophages secrete anti-inflammatory factors such as IL-10, and overexpress the mannose receptor (CD206), promoting tissue repair $[15,16]$ Meanwhile, the imbalance between the production of reactive oxygen species (ROS) containing free radicals such as hydrogen peroxide, hydroxyl radical, superoxide anion, and nitric oxide and their clearance by the antioxidant defense system including various enzymes, such as catalases (CAT), glutathione peroxidase (GPX), and superoxide dismutase (SODs) is a significant cause of chronic inflammation [17-19]. Therefore, due to the presence and interactions of these inflammatory mediators and oxidative stress, the 
joint cavity remains in an inflammatory state for a long time, which accelerates the progress of cartilage degradation and joint dysfunction $[17,20]$.

As a result, the key to the treatment of $\mathrm{OA}$ is to develop a multifunctional agent with antiinflammatory properties that can change the pro-inflammatory microenvironment and promote cartilage regeneration $[14,21]$. Clinical trials and basic research studies recently have revealed the therapeutic properties of mesenchymal stem cells (MSCs), skeletal stem cells, and adiposederived stem cells (ADSCs), which could be applied in cell therapy for OA [22-26]. In addition, accumulating evidence has demonstrated that several stem cells mainly exert their regenerative and immunomodulatory effects through a paracrine manner by releasing abundant growth factors and anti-inflammatory cytokines [22-25]. Of these, ADSCs represent valid candidates attributed to their anti-inflammatory and chondroprotective effects as MSCs and their simple acquisition from liposuction wastes [25, 27].

Although ADSCs have numerous advantages, immune rejection and the tumorigenicity of cell-based therapies have restricted their application [28-30]. To overcome these restrictions and facilitate the use of adipose tissue in treating OA, cell-free fat extract (CEFFE), the liquid fraction isolated from liposuction wastes was generated [31]. According to our previous study, CEFFE is a kind of cell-free liquid that is easily obtained using a mechanical approach to remove cellular components and lipid residues [31]. CEFFE is rich in various growth factors and anti-inflammatory components, including insulin-like factor-1 (IGF-1), transforming growth factor (TGF)- $\beta$, vascular endothelial growth factor (VEGF), and basic fibroblast growth factor, which is similar to the paracrine factors of ADSCs [31-37]. In addition, our previous studies have demonstrated that CEFFE has anti-apoptotic, anti-oxidative, and proliferation promotion abilities [31-38]. Based on these findings, we hypothesized that CEFFE might have a therapeutic effect on early OA. To this end, our present study evaluated the effects of CEFFE on cartilage regeneration and macrophage polarization and explored its potential mechanisms.

\section{Materials and methods}

\section{Preparation of CEFFE}

The Ethics Committee of Shanghai Ninth People's Hospital approved all experimental protocols of the present study. After informed consent was obtained from all participants in the study, adipose tissue was harvested from the abdomen or thigh of healthy adult females using liposuction from December 2020 to November 2021. The preparation of CEFFE was carried out following a previously established method [31] (Fig. 1). In brief, adipose tissues were rinsed with physiological saline solution (Kelun Pharmaceutical Co., Ltd, Sichuan, China) to wash away blood and tissue debris. Following centrifugation at $1200 \mathrm{~g}$ for $3 \mathrm{~min}$, three layers were formed. The upper oil layer and the lower aqueous layer were removed, whereas the middle fat layer was retained for mechanical emulsification by shifting between two syringes, which were 
attached to a three-way stopcock (Terumo Corporation, Tokyo, Japan), 30 times. The emulsified fat was then frozen and stored at $-80^{\circ} \mathrm{C}$ and thawed rapidly at $37^{\circ} \mathrm{C}$ to break the cell membranes. After one freeze-thaw cycle, samples were centrifuged at $1200 \mathrm{~g}$ for $5 \mathrm{~min}$, resulting in the formation of four layers. Finally, the third liquid layer was collected and filtered through a 0.22 $\mu \mathrm{m}$ filtration membrane (Corning Glass Works, Corning, NY, USA) to remove bacteria and other debris, generating CEFFE, which was frozen at $-80{ }^{\circ} \mathrm{C}$ for further experiments. The protein concentration in CEFFE was determined using a bicinchoninic acid assay kit (BCA; Sigma-Aldrich, St Louis, MO, USA).

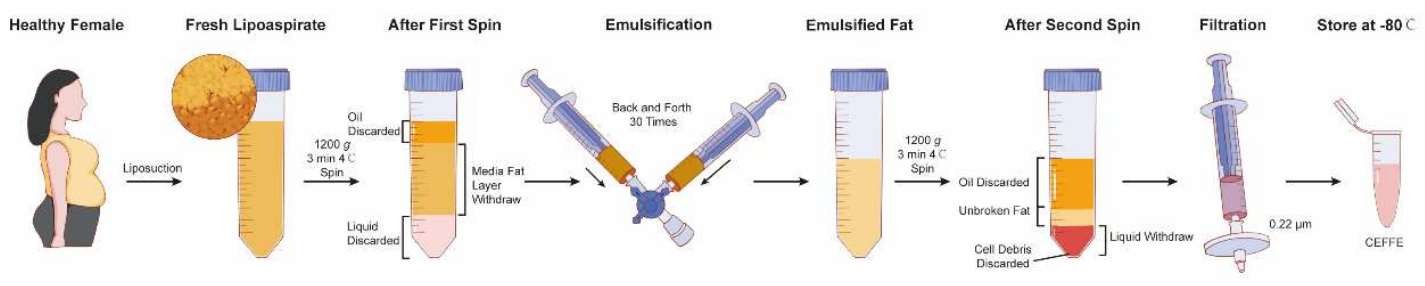

Fig. 1 Schematic illustration of preparation of CEFFE

\section{Animals}

Adult male Sprague-Dawley (SD) rats (7-8 weeks old, 290-344 g) were purchased from Vital River Laboratory Animal Technology Co., Ltd (SCXK-2016-0006, Beijing, China). All rats were housed in a barrier environment (temperature, $20-25^{\circ} \mathrm{C}$; humidity, $40-70 \%$; light, $12 \mathrm{~h} / \mathrm{d}$ ) with free access to water and food (SYXK-2019-0013). All experiments were approved by the Animal Care and Experiment Committee of Shanghai Jiao Tong University School of Medicine. Rats were randomly divided into 5 groups ( $\mathrm{n}=6$ in each group): control, model, $\mathrm{CEFFE}^{\text {low }}, \mathrm{CEFFE}^{\text {middle }}$, and CEFFE ${ }^{\text {high }}$. Rats in the control group were not subjected to any treatment. A single intra-articular injection of $50 \mu \mathrm{L}$ sodium iodoacetate (MIA, $40 \mathrm{mg} / \mathrm{mL}$ dissolved in saline; Sigma-Aldrich, St Louis, MO, USA) was administered to rats in other groups to induce the OA model. One week later, saline or an equal volume of different concentrations of CEFFE ( $0.0357 \mathrm{mg}$ for the CEFFE ${ }^{\text {low }}$ group, 0.075 $\mathrm{mg}$ for the $\mathrm{CEFFE}^{\text {middle }}$ group, and $0.15 \mathrm{mg}$ for the $\mathrm{CEFFE}^{\text {high }}$ group) was administered four times at biweekly intervals (Fig.2a, b). All animals were euthanized a week after the fourth injection. Measurement of bipedal balance using weight-bearing asymmetry [39] and von Frey test using the dynamic plantar tactile device [40] were performed on all surviving animals before modeling, one week after modelling, and one week after each administration.

\section{Histological staining}

The entire left keen joint of rats was removed, fixed in $10 \%$ buffered formaldehyde, and decalcified in $10 \%$ formic acid. After embedding, the knee joint medial compartment was cut into $5 \mu \mathrm{m}$-thick sagittally oriented sections. Sections were stained with hematoxylin-eosin (HE) and Safranin O-fast green (S\&F; Solarbio, Beijing, China) to observe the cartilage structure. Three visual fields were randomly selected for the evaluation of HE structural scoring using a 
1 to 4 grading system $(1=$ slight; $2=$ mild; $3=$ moderate; $4=$ severe). For S\&F structural scoring, the Osteoarthritis Research Society International (OARSI) joint pathology scoring standards were referred to [41]. To observe glycosaminoglycan (GAG), sections were stained with toluidine blue (Solarbio, Beijing, China). To evaluate the regeneration and maturation of cartilage, immunohistochemistry for type II collagen was performed. To assess macrophage infiltration in the synovium of the joint, immunohistochemistry for CD68 and CD206 was carried out.

\section{Cell culture}

To investigate the role of CEFFE in regulating inflammation in vitro, mouse macrophage Raw 264.7 cells were purchased from the American Type Culture Collection (ATCC) cell bank (ATCC Number: TIB-71 ${ }^{\mathrm{TM}}$, Shanghai, China). Raw 264.7 cells were cultured in Dulbecco's modified Eagle medium (DMEM; Invitrogen, Thermo Fisher Scientific, USA) supplemented with $10 \%$ fetal bovine serum (FBS; Gibco, Gland Island, NY, USA) and 1\% penicillinstreptomycin-gentamicin solution (Gibco, Gland Island, NY, USA) and maintained at $37^{\circ} \mathrm{C}$ in a humidified $5 \% \mathrm{CO}_{2}$ atmosphere.

\section{In vitro polarization induction of Raw 264.7 macrophages}

To investigate the role of CEFFE in regulating macrophage polarization in an inflammatory environment, $4 \times 10^{5}$ Raw 264.7 cells were seeded in 6-well plates. After $24 \mathrm{~h}$ of cell contact, the normal medium was replaced with $2 \mathrm{~mL}$ culture medium (control group); culture medium containing $1 \mu \mathrm{g} / \mathrm{mL}$ lipopolysaccharide (LPS; Sigma-Aldrich, St. Louis, MO, USA) and 30 $\mathrm{ng} / \mathrm{mL}$ interferon- $\gamma$ (IFN- $\gamma$; PeproTech, Rocky Hill, USA) (LPS + IFN- $\gamma$ group); culture medium containing $1 \mu \mathrm{g} / \mathrm{mL}$ LPS, $30 \mathrm{ng} / \mathrm{mL}$ IFN- $\gamma$, and different concentrations of CEFFE $(100 \mu \mathrm{g} / \mathrm{mL}, 250 \mu \mathrm{g} / \mathrm{mL}$, and $500 \mu \mathrm{g} / \mathrm{mL})$. After incubating in these media for $24 \mathrm{~h}$, all media were replaced with fresh media for another $24 \mathrm{~h}$. The polarization of Raw 264.7 cells to M1/M2 macrophages was identified by flow cytometry, immunofluorescence staining, and quantitative real-time polymerase chain reaction (qRT-PCR). We also tested the effects of different concentrations of CEFFE on inactive macrophages in the same way.

\section{Flow cytometry}

For cytometry, treated cells were blown down using cold phosphate buffered saline (PBS, Invitrogen, San Diego, CA, USA), and $4 \times 10^{5}$ cells were counted and suspended in $100 \mu \mathrm{L}$ PBS supplemented with 4\% FBS. Cells were then incubated with fluorescein isothiocyanateanti-mouse CD86 (1:40; BioLegend, San Diego, CA, USA), allophycocyanin-anti-mouse CD206 (1:40; BD Pharmingen ${ }^{\mathrm{TM}}$, San Diego, CA, USA) at $4{ }^{\circ} \mathrm{C}$ for $30 \mathrm{~min}$. After washing thrice with PBS, labeled cells were suspended in $100 \mu \mathrm{L}$ PBS, and data were acquired via the 
fluorescence-activated cell sorting Calibur flow cytometry system (BD Bioscience, San Jose, CA, USA) and analyzed using the CytExpert software (Beckman Coulter, Inc., Brea, CA, USA).

\section{Immunofluorescence staining}

For immunofluorescence staining, RAW 264.7 cells were seeded into 6-well plates with cell climbing slices at a density of $2 \times 10^{5}$ cells/well. As previously described, after $48 \mathrm{~h}$ of treatment, cells were fixed with 4\% paraformaldehyde in PBS and incubated with anti-CD86 (1:200; ProteinTech, Wuhan, China) overnight at $4{ }^{\circ} \mathrm{C}$ followed by $1 \mathrm{~h}$ incubation with Alexa Flour 488-conjugated goat secondary antibody (Jackson ImmunoResearch, Carlsbad, CA, USA) at room temperature [42]. Nuclei were stained with DAPI (1:1000, Boster, Wuhan, China).

\section{Quantitative real-time PCR}

To determine the levels of expression of the M1-related paracrine factors [IL-1 $\beta$, IL-6, inducible nitric oxide synthase (iNOS), and TNF- $\alpha$ ], M2-related factors [IL-10, arginase-1 (ARG), TGF$\beta$, and CD-206], and oxidative stress-related enzymes [GPX-1, CAT, SOD-1, and SOD-2], treated cellular mRNA was extracted using the Total RNA Extraction Reagent (EZBioscience, Roseville, USA) according to the manufacturer's instructions. Briefly, $1 \mu \mathrm{g}$ total RNA was reverse transcribed to cDNA using a reverse transcription master mix (EZBioscience, Roseville, USA) according to the manufacturer's instructions. Subsequently, qRT-PCR was conducted using an SYBR Green qPCR master mix (ROX2 plus; EZBioscience, Roseville, USA). Cycling parameters were $95{ }^{\circ} \mathrm{C}$ for $5 \mathrm{~min}$, then 40 cycles at $95^{\circ} \mathrm{C}$ for $10 \mathrm{~s}$ followed by $60{ }^{\circ} \mathrm{C}$ for $30 \mathrm{~s}$. At least three technical replicates were performed for each sample. Relative expression levels were calculated using the $2^{-\Delta \Delta \mathrm{Cq}}$ method and are presented as fold-change relative to the glyceraldehyde 3-phosphate dehydrogenase house gene expression [43]. Primers for qRT-PCR are listed in Table S1.

\section{Measurement of reactive oxygen species}

The levels of intracellular ROS were assessed using a ROS assay kit (Beyotime, China) according to the manufacturer's instructions. Briefly, cells were washed thrice with non-FBS DMEM and incubated with $10 \mu \mathrm{M}$ 2,7-dichlorodihydrofluorescein diacetate (DCFH-DA) at $37^{\circ} \mathrm{C}$ for $20 \mathrm{~min}$ in the dark. After washing thrice with non-FBS DMEM, cells were observed and imaged under a fluorescence microscope (Olympus Corporation, Tokyo, Japan). Cells were digested and suspended in $100 \mu \mathrm{L}$ PBS supplemented with 4\% FBS to detect ROS levels using flow cytometry (Beckman-Coulter, Brea, CA, USA).

\section{Levels of nitric oxide}

Nitrite accumulated in the culture supernatant was measured as an indicator of the production 
of NO using a NO assay kit (Beyotime, China) according to the manufacturer's instructions. In brief, $50 \mu \mathrm{L}$ of culture supernatant or $\mathrm{NaNO}_{2}$ standard was mixed with $100 \mu \mathrm{L}$ Griess reagent at $25^{\circ} \mathrm{C}$. After incubation, absorbance was read at a wavelength of $540 \mathrm{~nm}$ using a microplate reader (SpectraMAX190; Molecular Devices, Sunnyvale, CA), and NO concentrations were estimated from the $\mathrm{NaNO}_{2}$ standard curve.

\section{Western blotting}

Cells were cultured in a 6-well plate. After treatment, the total protein of cells was obtained and quantified using a BCA assay (Sigma-Aldrich, St Louis, MO, USA). Proteins were separated according to their molecular weights through sodium dodecyl sulfate-polyacrylamide gel electrophoresis and transferred to polyvinylidene fluoride membranes (Millipore, MA, USA). After successive incubation with primary and rabbit secondary antibody conjugated with HRP (Abcam, Cambridge, UK), membranes were observed using enhanced chemiluminescence (Pierce, Rockford, IL, USA). Primary antibodies used were anti-GPX-1, anti-CAT, anti-SOD1, anti-SOD-2, anti-iNOS, anti-COX-2, and anti- $\beta$-actin (1:1000; Cell Signaling Technology, Inc., Danvers, MA, USA).

\section{Isolation and culture of mouse primary chondrocytes}

Primary chondrocytes were obtained from male C57BL/6 mice aged 4 weeks. The femoral head was removed and cut into pieces, digested with trypsin for $40 \mathrm{~min}$, and then digested with type II collagenase for $8 \mathrm{~h}$. Primary chondrocytes were cultured at F-12/DMEM (Invitrogen, Thermo Fisher Scientific, USA) supplemented with 10\% FBS and 1\% penicillin-streptomycingentamicin solution. Then, $10 \mathrm{nM}$ IL- $1 \beta$ and $10 \mathrm{nM}$ TNF- $\alpha$ (PeproTech Inc., Rocky Hill, NJ, USA) were used to induce inflammation in cultured primary chondrocytes.

\section{Cell Counting Kit-8 assay}

Primary chondrocytes were cultured in a 96-well plate at $3 \times 10^{3}$ per well until attached. After treatment with CEFFE with or without inflammation factors for $3 \mathrm{~d}$, cells were incubated with DMEM supplemented with $10 \%$ Cell Counting Kit- 8 reagent (Beyotime, China) at $37^{\circ} \mathrm{C}$ for 2 $\mathrm{h}$ in the dark. The optical density of each sample was detected at a wavelength of $450 \mathrm{~nm}$ using a microplate reader (Thermo Electron Corporation, USA).

\section{Statistical analysis}

Statistical analysis was performed using the IBM SPSS ${ }^{\circledR} 24.0$ statistical software ( IBM Corporation, Chicago, IL, USA). Differences between groups were analyzed using one-way analysis of variance, followed by Tukey's post hoc test. Data are expressed as the mean \pm standard deviation (SD). Statistical significance was indicated as $\mathrm{p}<0.05^{*}$ or $\mathrm{p}<0.01^{* *}$. 


\section{Results}

\section{CEFFE reduced the severity of symptoms in MIA-induced osteoarthritis rats}

To evaluate the therapeutic value of CEFFE, we established a rat model of OA and examined the effect of the treatment with CEFFE on the injured articular cartilage. We did not observe any obvious clinical signs or weight differences among groups within 8 weeks (Fig. 2c). We also found that before modeling, there was no significant difference in bipedal pressure (28.1 \pm 5 vs. $27.8 \pm 6.2 \mathrm{~g}, \mathrm{p}>0.05)$ and claw retraction pressure $(8 \pm 5$ vs. $9 \pm 7, \mathrm{p}>0.05)$ between the control and model groups. However, we noticed a clear difference 1 week after modeling, suggesting that MIA can successfully induce OA in SD rats (Fig. 2d, e). More specifically, we observed that 1 week after the fourth administration, the absolute value of bipedal pressure of rats in the CEFFE ${ }^{\text {low }}$ group was lower than that in the model group. Moreover, we found that the absolute value of the $\mathrm{CEFFE}^{\text {middle }}$ and CEFFE ${ }^{\text {high }}$ groups was lower than that of the model group from the first administration until the end of the experiment (Fig. 2f). In particular, we observed that the claw retraction pressure of rats in the three CEFFE treatments groups was significantly higher than that in the model group at the end of the experiment (Fig. 2g). These results indicated that CEFFE could reduce the severity of symptoms in MIA-induced OA rats.
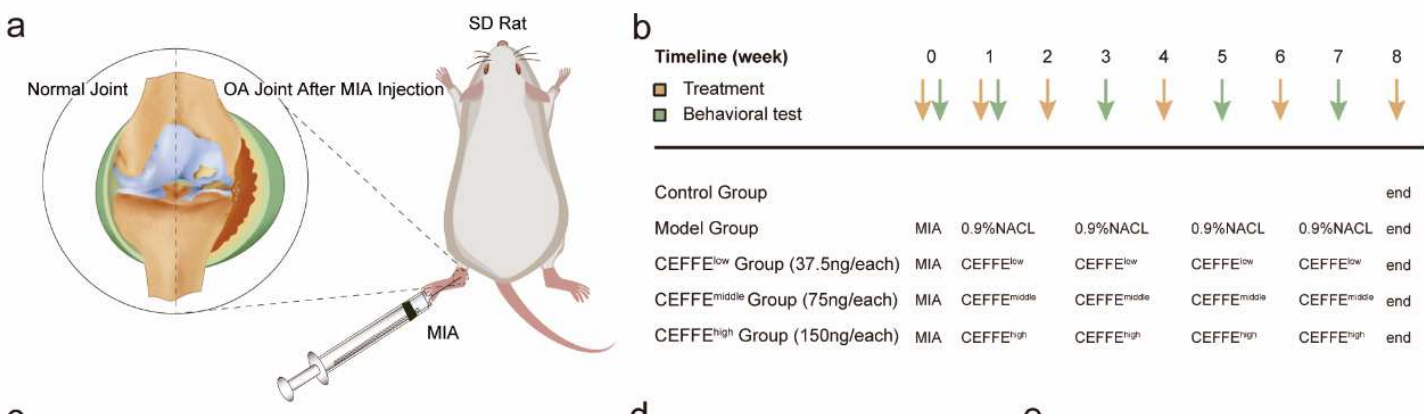

C

d

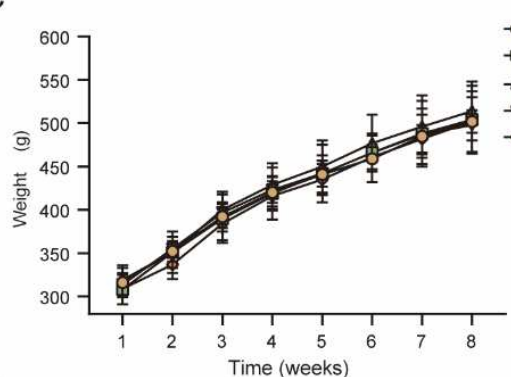

$\operatorname{pontrol} e$

f
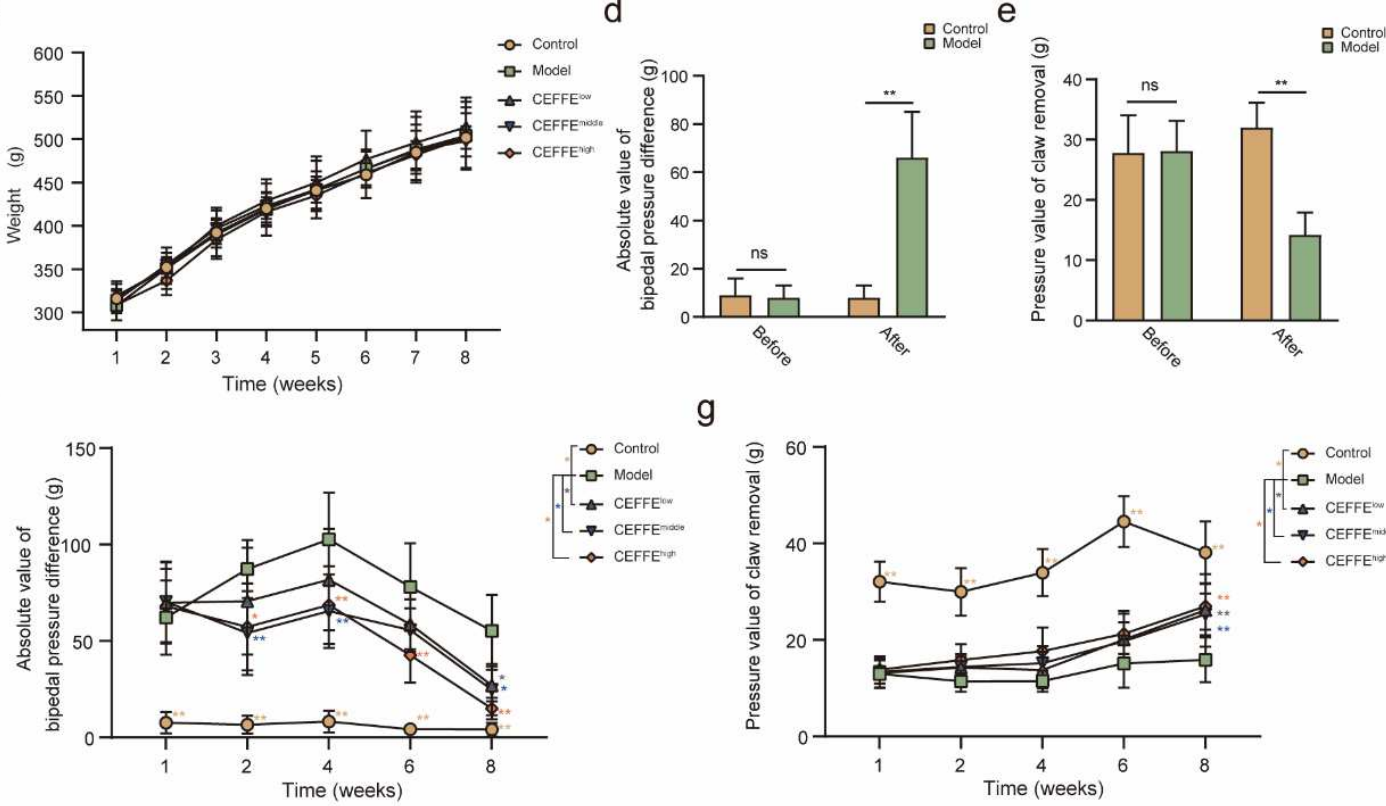

g
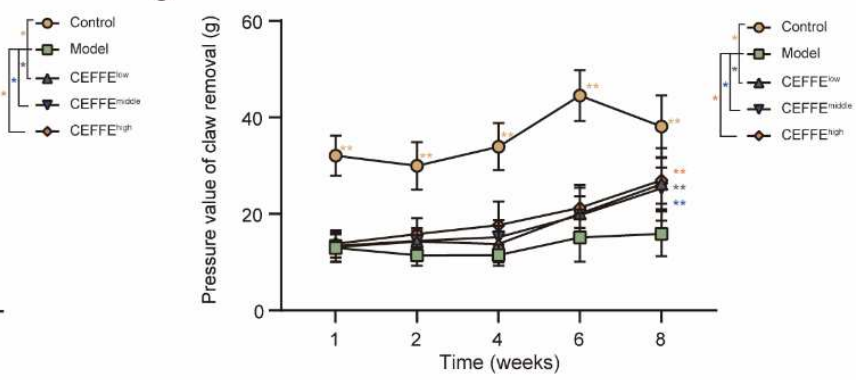

Fig. 2 Therapeutic efficacy of CEFFE on the symptoms of MIA-induced OA rats. a Schematic overview of MIA intra-articular injection. b Flowchart of the dosing regimen and behavioral experiments. $\mathbf{c}$ No statistical differences 
in body weight changes among different groups at each time point. $\mathbf{d}$ Changes in absolute bipedal pressure difference after injection of MIA. e Changes in claw retraction pressure after injection of MIA. $\mathbf{f}$ Quantitative analysis of absolute bipedal pressure difference after injection of CEFFE at each time point. $\mathbf{g}$ Quantitative analysis of claw retraction pressure after injection of CEFFE at each time point. Data represent the mean \pm SD $(n=$ 6 per group). ${ }^{*} \mathrm{p}<0.05 ;{ }^{* *} \mathrm{p}<0.01 ; \mathrm{ns}$, no significant difference between groups.

\section{Mechanisms of CEFFE-mediated cartilage repair in MIA-induced OA rats}

We conducted special staining and immunohistochemistry to investigate the mechanism of the CEFFE-mediated therapeutic effects. HE and S\&F staining showed that compared with the model group, the gross morphologies of joint sections in the $\mathrm{CEFFE}^{\text {middle }}$ and $\mathrm{CEFFE}^{\text {high }}$ groups were closer to the control group (Fig. 3a, b). The score of HE staining (cartilage fibrosis and cartilage degeneration; Fig. 3g) and S\&F staining (OARSI; Fig. 3h) also showed a decline trend as CEFFE concentration increased.

Moreover, toluidine blue staining and immunohistochemically detection of type II collagen revealed the reduction of both GAG and type II collagen in the cartilage matrix in the model group; however, this effect was reversed after intra-articular injection of CEFFE (Fig. 3c, d). According to the CD68 staining, we noticed that the infiltration of total macrophages (CD68positive cells) was not different between the CEFFE-treated and model groups. However, we found that CEFFE upregulated the synovial M2 macrophage (CD206-positive cells) ratio compared with that in the model group (Fig. 3e, f). 


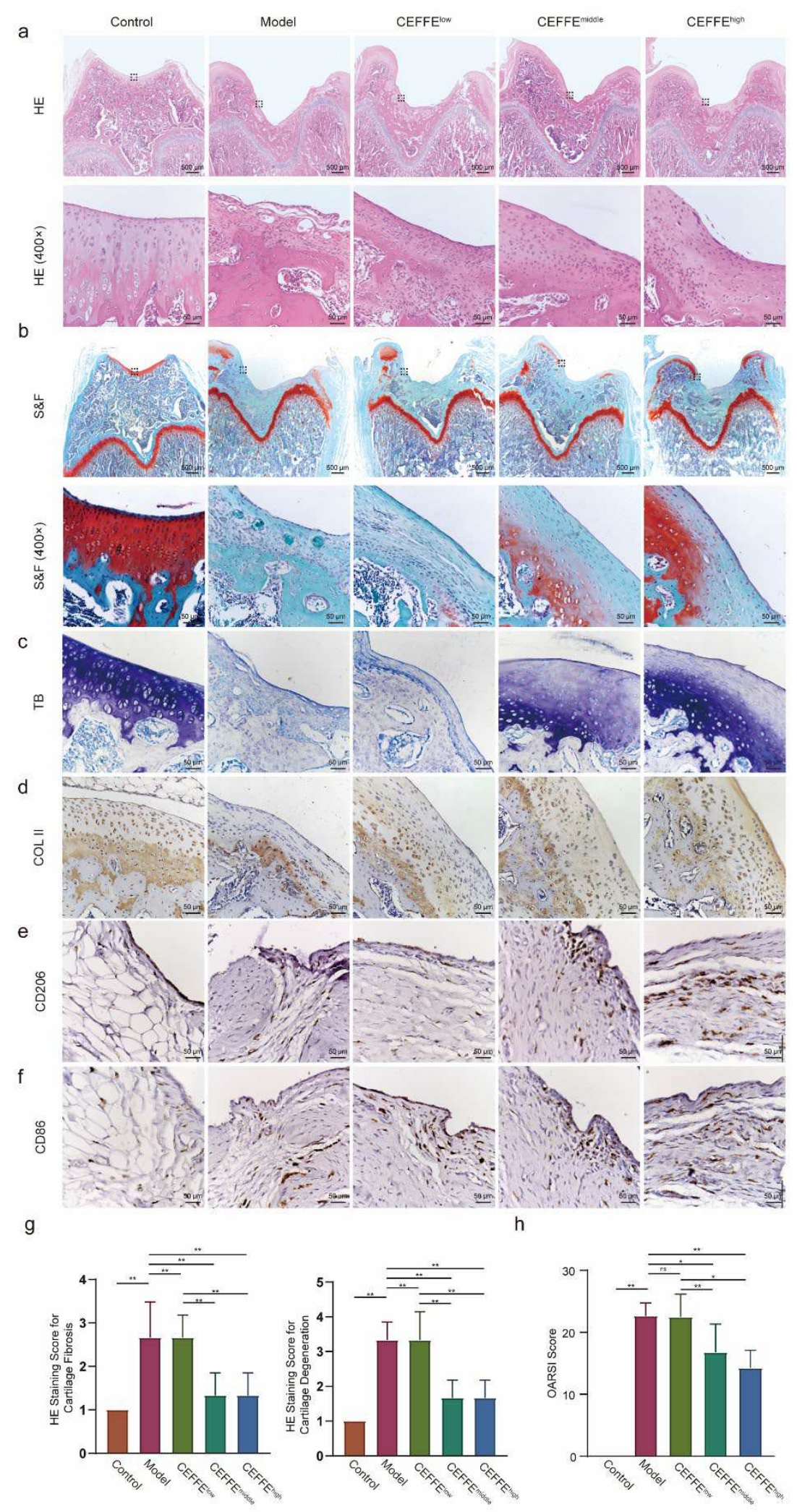

Fig. 3 Histological evaluation of structural changes and matrix deposition in cartilage and macrophage infiltration in synovium. a, $\mathbf{g}$ The longitudinal section of a rat joint was stained with HE. Quantitative analysis of HE staining score containing cartilage fibrosis and cartilage degeneration according to a 1 to 4 grading system. $\mathbf{b}, \mathbf{h}$ Safranin-O fast green $(\mathrm{S} \& \mathrm{~F})$ staining of the longitudinal section of a rat bone. Quantitative analysis of S\&F staining according 
to the OARSI standard. $\mathbf{c}$ GAG staining of cortical bone sections. d Anti-COL II staining of cortical bone sections. e anti-CD206 staining of knee synovium. $\mathbf{f}$ anti-CD68 staining of knee synovium. Scale bars $=200 \mu \mathrm{m}$. Data represent the mean $\pm \mathrm{SD}$ ( $\mathrm{n}=6$ per group). ${ }^{*} \mathrm{p}<0.05 ;{ }^{* *} \mathrm{p}<0.01 ; \mathrm{ns}$, no significant difference between groups.

\section{CEFFE inhibited the transformation of Raw 264.7 cells from M0 to M1 macrophages}

To verify that CEFFE exerted a beneficial effect in alleviating inflammation, we stimulated Raw 264.7 cells with LPS and IFN- $\gamma$ and simultaneously incubated them with $100 \mu \mathrm{g} / \mathrm{mL}, 250$ $\mu \mathrm{g} / \mathrm{mL}$, and $500 \mu \mathrm{g} / \mathrm{mL}$ CEFFE. Flow cytometry analysis indicated that LPS + IFN- $\gamma$ significantly stimulated the polarization of M0 macrophages towards M1 (CD86-positive, proinflammatory cells) from $1.62 \%$ to $59.74 \%$. However, we observed that the proportion of M1 macrophages ( $59.74 \pm 1.69 \%$ to $56.9 \pm 0.71 \%, 46.94 \pm 0.05 \%, 46.43 \pm 4.21 \%)$ was gradually decreased in a CEFFE concentration-dependent manner at $100 \mu \mathrm{g} / \mathrm{mL}, 250 \mu \mathrm{g} / \mathrm{mL}$, and 500 $\mu \mathrm{g} / \mathrm{mL}$ CEFFE, respectively (Fig. 4a, d). Meanwhile, we noticed that incubation of M0 cells with the same concentration of CEFFE did not lead to a marked change (Fig. S1a, c).

Moreover, we detected a low proportion (1-13\%) of M2 macrophages (CD206-positive, antiinflammatory cells) when incubated with different concentrations of CEFFE with or without LPS + IFN- $\gamma$ (Fig. 4b, e and Fig. S1b, d). Our immunofluorescence analysis was consistent with that of flow cytometry. We detected an upward trend in the proportion of M1 cells (CD86 positive) in the LPS + IFN- $\gamma$ group compared with that in the control group, whereas this trend was reversed after co-incubation with CEFFE (Fig. 4c, f).

To further explore the potential role of CEFFE in resolving inflammation, we conducted qRTPCR for pro-inflammatory and anti-inflammatory factors. Our qRT-PCR analysis showed that the mRNA expression levels of the IL-1 $\beta$, IL- 6 , iNOS, and TNF- $\alpha$ pro-inflammatory factors were remarkably elevated in the LPS + IFN- $\gamma$ group. In contrast, we noticed that after coincubation with different concentrations of CEFFE, the mRNA expression exhibited a significant dose-dependent decrease (Fig. 4g). Concurrently, we detected that the mRNA expression of the ARG, IL-10 and TGF- $\beta$ anti-inflammatory factors showed a slight upward trend in the LPS + IFN- $\gamma+$ CEFFE group when compared with that in the LPS + IFN- $\gamma$ group (Fig. 4h). 
a

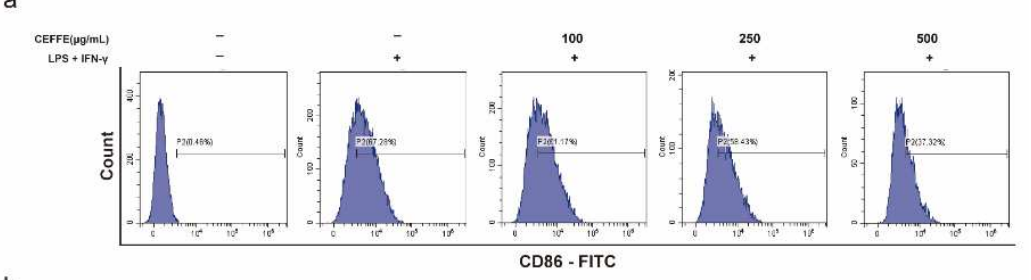

b

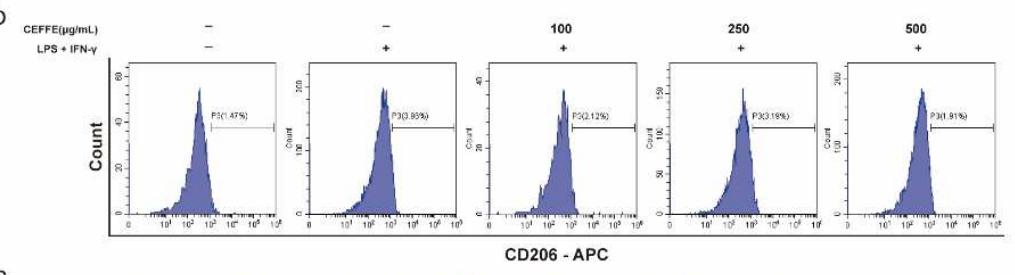

$\bar{a}$

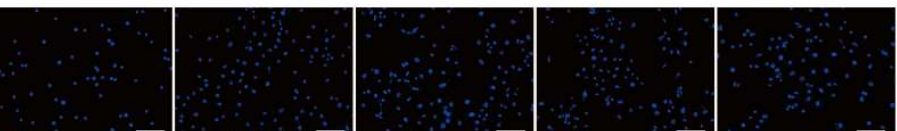

。̊

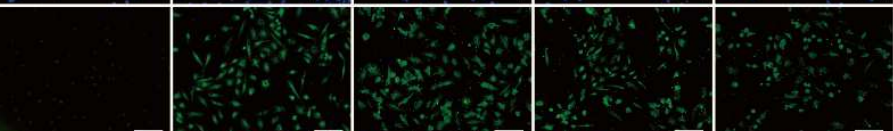

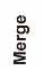

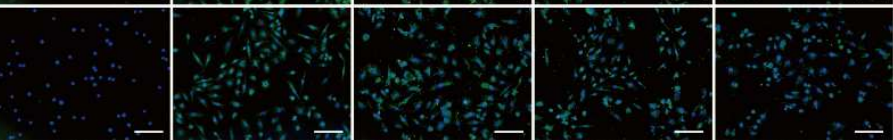

흥

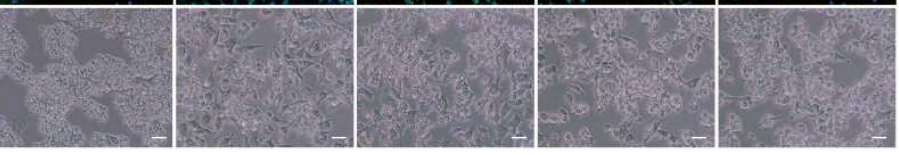

CEFFE(Hg/mL)
LPS + IFN-Y

$\stackrel{100}{+}$

$\stackrel{250}{+}$

$\stackrel{500}{+}$

d
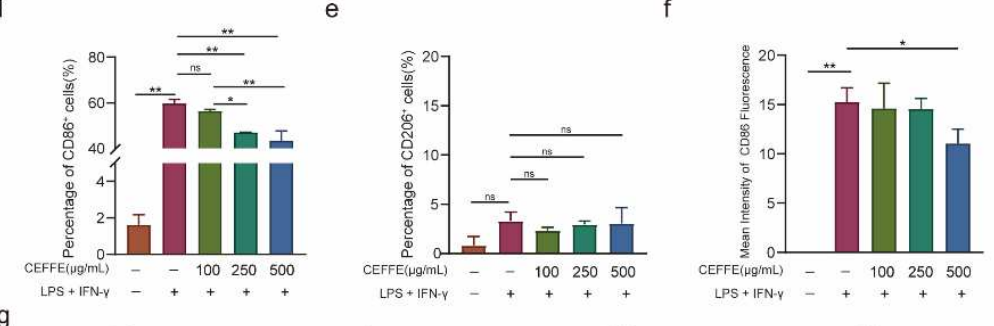

g
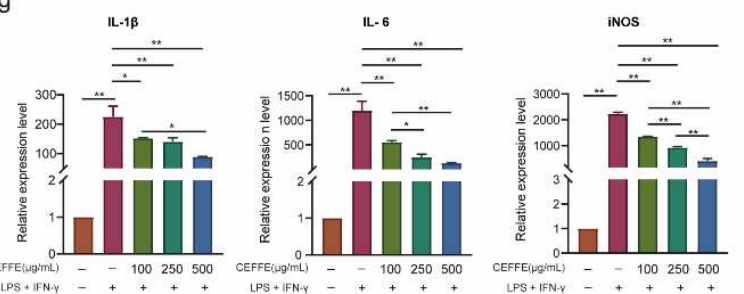

TNe
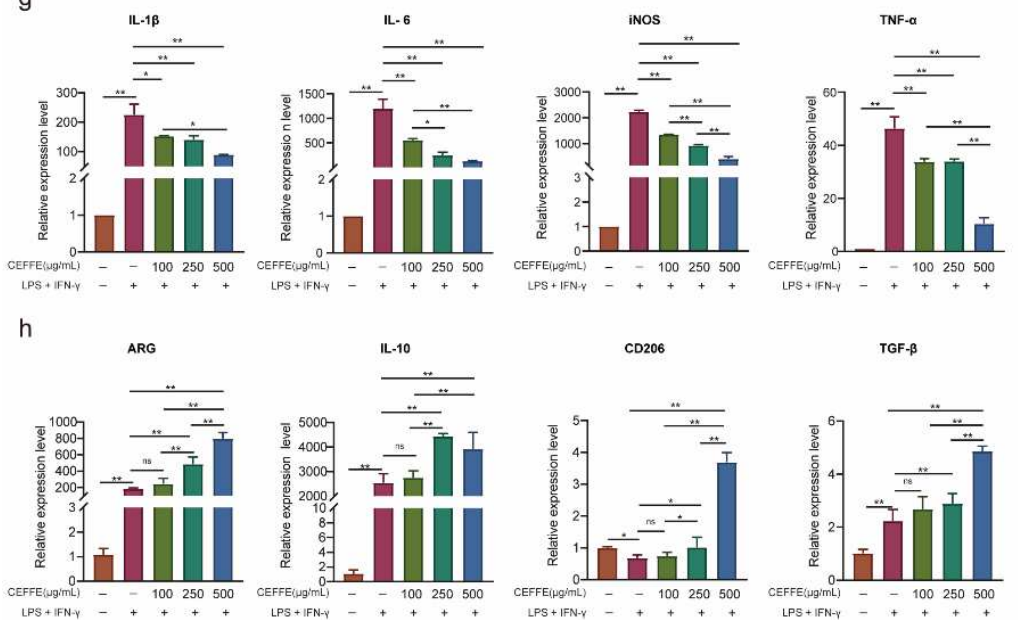

Fig. 4 CEFFE attenuated the differentiation of Raw 264.7 cells from M0 to M1 macrophages. a, d Quantification of CD86-positive cells by flow cytometry. A significant decline in the proportion of M1 macrophages was observed after treatment with CEFFE. b, e Quantification of CD206 positive cells by flow cytometry. No obvious change was observed in the ratio of M2 cells. c, f Immunofluorescence staining of CD86 and bright filed pictures 
of Raw 264.7 cells. The CEFFE-treated group showed a declining tendency and morphological changes compared with the LPS + IFN- $\gamma$ group. g Quantification of IL-1 $\beta$, IL-6, iNOS, and TNF- $\alpha$ mRNA expression by qRT-PCR. The CEFFE-treated group showed a significant dose-dependent decrease compared with the LPS + IFN- $\gamma$ group. $\mathbf{h}$ Quantification of ARG, IL-10, CD206, and TGF- $\beta$ mRNA expression by qRT-PCR. The CEFFE-treated group showed a slight upward trend compared with the LPS + IFN- $\gamma$ group. Data represent the mean \pm standard deviation ( $\mathrm{n}=3$ per group). ${ }^{*} \mathrm{p}<0.05 ;{ }^{* *} \mathrm{p}<0.01 ; \mathrm{ns}$, no significant difference between groups.

\section{CEFFE promoted proliferation, regeneration, reduced matrix degradation, and reduced} inflammation of murine primary chondrocytes.

To investigate the effect of CEFFE on chondrocytes, we isolated and used murine primary chondrocytes. We treated cells with different concentrations of CEFFE $(0,50,100,250$, and $500 \mu \mathrm{g} / \mathrm{mL}$ ) in the presence or absence of IL- $1 \beta$ and TNF- $\alpha$. We found that CEFFE promoted the proliferation of primary chondrocytes. Whereas inflammation factors distinctly inhibited the proliferation of cells, we noticed that CEFFE exerted a protective effect on the growth of primary chondrocytes under inflammation (Fig. 5a, b).

We further stimulated chondrocytes for increased matrix degradation and inhibition of chondrocyte regeneration under inflammation. To this end, we detected the expression of interleukin-6 (IL-6) as a pro-inflammation marker, a disintegrin metalloproteinase with thrombospondin motifs 5 (ADAMTs-5) as the most significant matrix degradation enzymatic marker, and SOX-9 as a chondrocyte regeneration marker. We found that the expression of SOX-9 was increased, whereas that of ADAMTs-5 was decreased when primary chondrocytes were treated with CEFFE. Moreover, we noticed that while primary chondrocytes were cocultured with inflammation factors, the expression of SOX-9 was decreased, whereas that of ADAMTs-5 and IL-6 was increased. Furthermore, after treatment of chondrocytes under inflammation with CEFFE, we found that the expression of SOX-9 was increased, whereas that of ADAMTs-5 and IL-6 was decreased (Fig. 5c, d, e). 
a

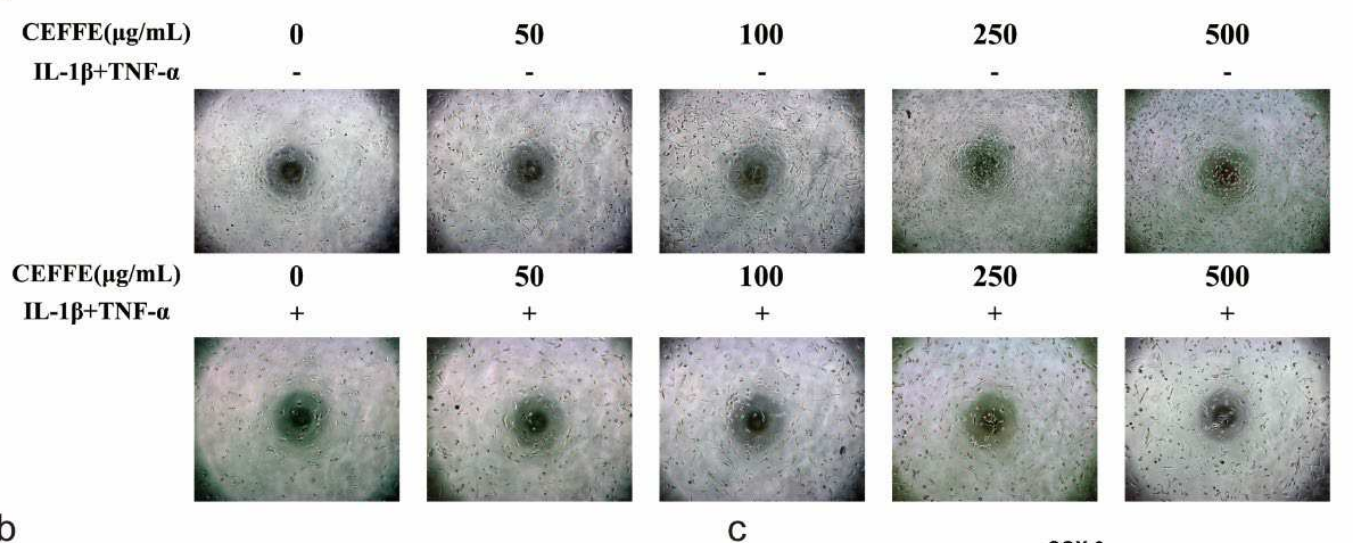

b

C

sox-9
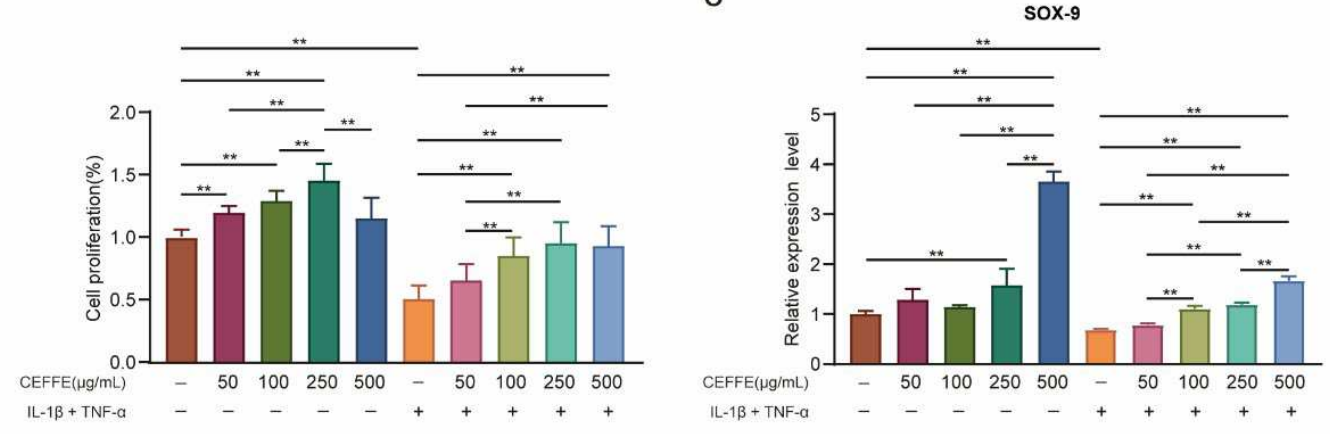

d

ADAMTS-5

e

IL-6
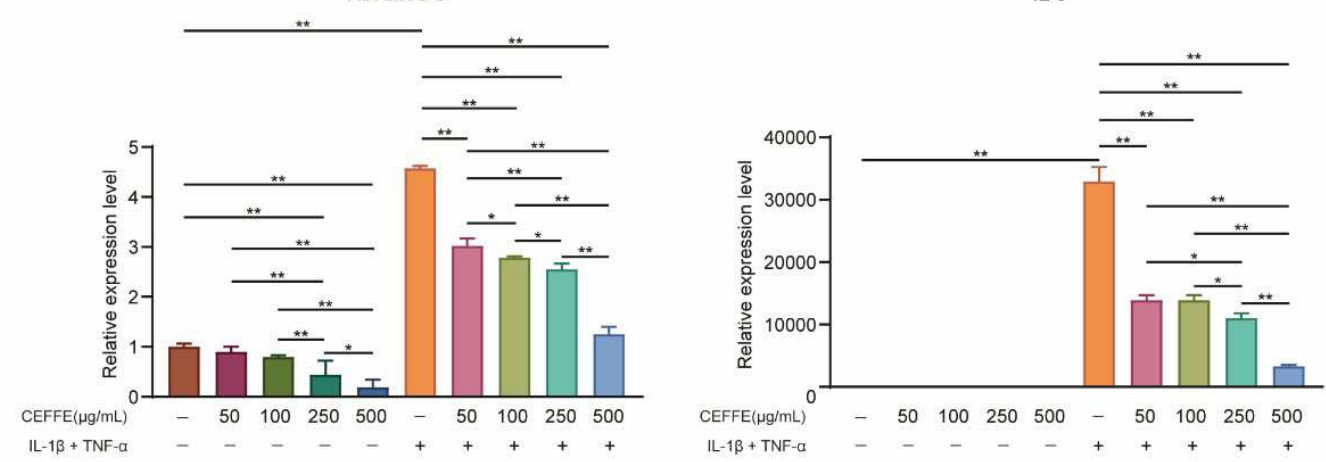

Fig. 5 The protective effect of CEFFE in murine primary chondrocytes. a, b Original images and CCK8 results of murine primary chondrocytes treated with CEFFE, with or without IL- $1 \beta$ and TNF- $\alpha$. CEFFE promoted the proliferation of murine primary chondrocytes regardless of IL- $1 \beta$ and TNF- $\alpha$. $\mathbf{c}$ Quantification of SOX9 mRNA expression by qRT-PCR. d Quantification of ADAMTS-5 mRNA expression by qRT-PCR. e Quantification of IL-6 mRNA expression by qRT-PCR. Data represent the mean \pm SD ( $n=3$ per group). ${ }^{*} p<0.05 ;{ }^{* *} p<0.01$; ns, no significant difference between groups.

\section{CEFFE inhibited inflammation-induced oxidative stress in RAW264.7 macrophages and} murine primary chondrocytes

To explore the mechanism of action of CEFFE on RAW264.7 macrophages and primary chondrocytes, we detected the intracellular levels of ROS through DCFH-DA staining. We observed the fluorescence intensities of RAW264.7 macrophages and primary chondrocytes using fluorescent microscopy and flow cytometry. We found that in RAW264.7 macrophages, CEFFE reduced the fluorescence intensity induced by LPS and IFN- $\gamma$ in a dose-dependent 
manner (Fig. 6a, b, c, d). Concomitantly, we noticed that nitrite accumulation in the culture supernatant decreased after incubation with $500 \mu \mathrm{g} / \mathrm{mL}$ CEFFE compared to the LPS + IFN- $\gamma$ group (Fig. 6e).

a

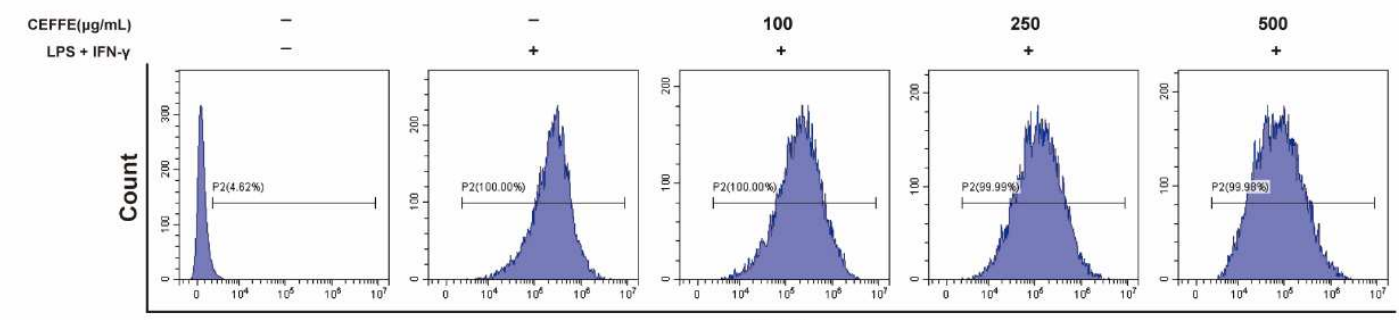

b
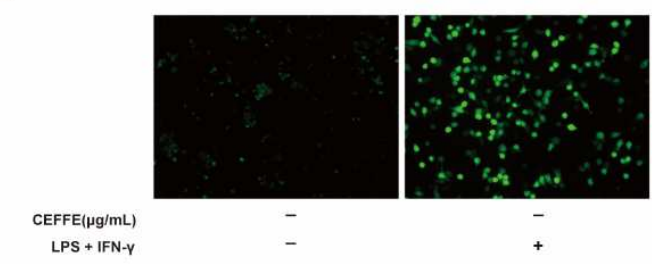

FITC-A

C

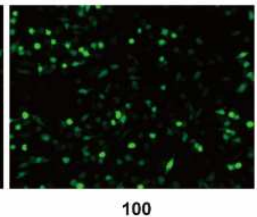

100

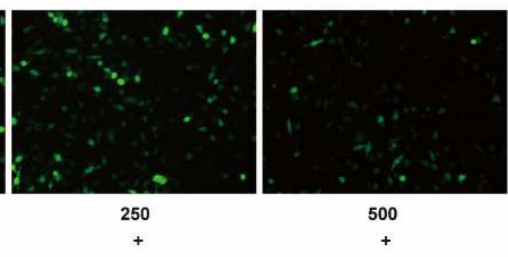

d

e
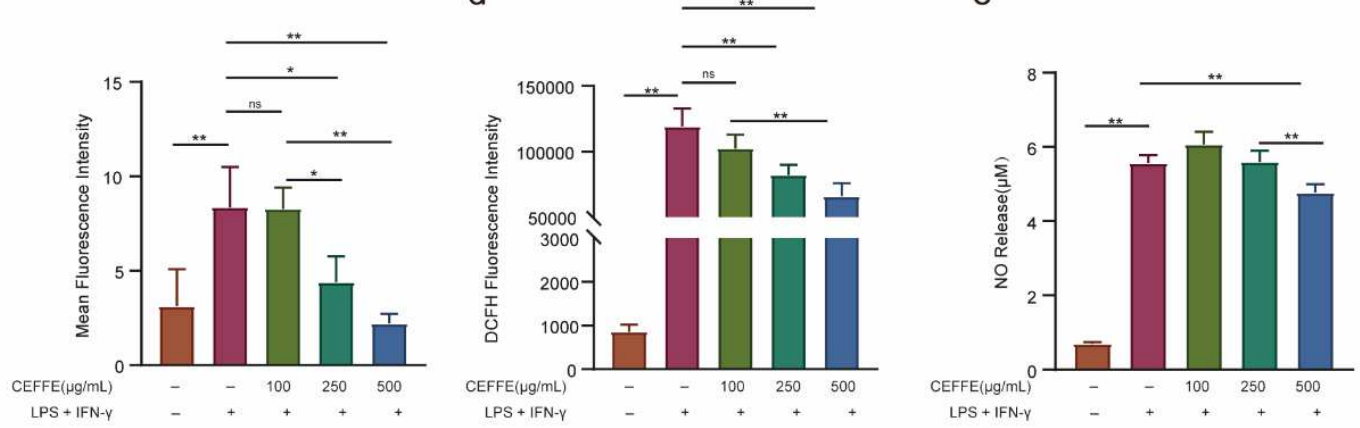

Fig. 6 CEFFE reduced the intracellular production of ROS in RAW 264.7 cells. a, $\mathbf{c}$ Flow cytometry showed that CEFFE counteracted the intracellular production of ROS induced by LPS + IFN- $\gamma$ in a dose-dependent manner. $\mathbf{b}$, d Fluorescence microscopy observation of DCHF fluorescence intensity. e Intracellular NO was measured using a nitric oxide assay kit. Data represent the mean $\pm \mathrm{SD}\left(\mathrm{n}=3\right.$ per group). ${ }^{*} \mathrm{p}<0.05 ;{ }^{* *} \mathrm{p}<0.01$; ns, no significant difference between groups.

In addition, we observed that the expression of each of the GPX-1, catalase, SOD-1, and SOD-2 antioxidant enzymes was increased as measured by qRT-PCR and western blotting. Interestingly, the most apparent change was noticed for the expression of GPX-1 and catalase (Fig. 7a, b, c). 
a

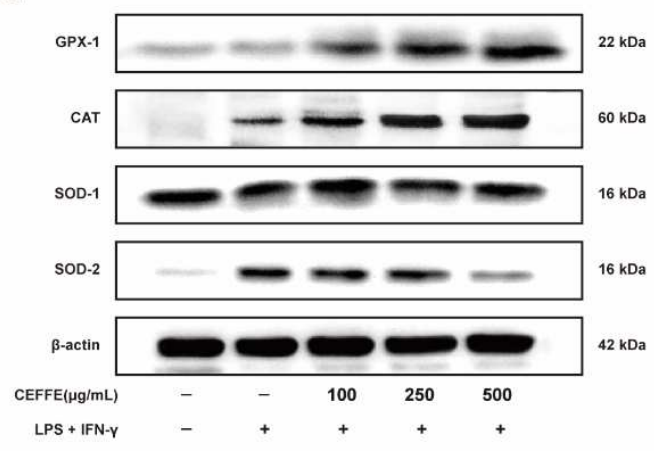

C

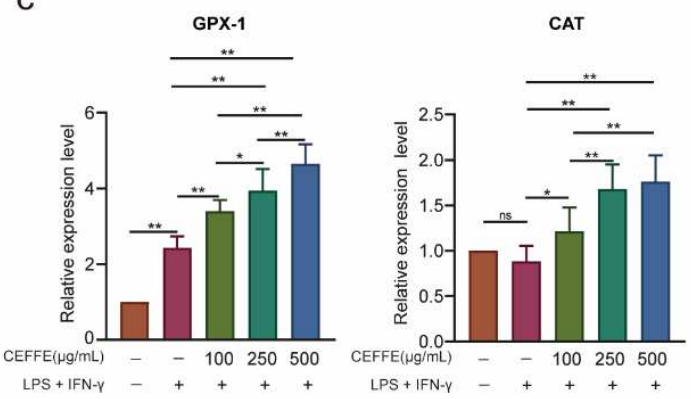

b

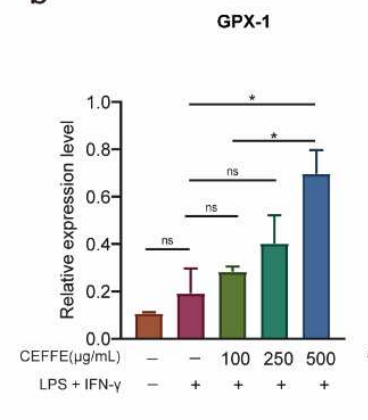

SOD-1

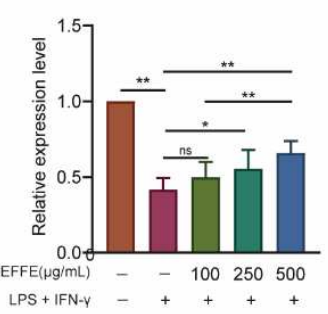

CAT

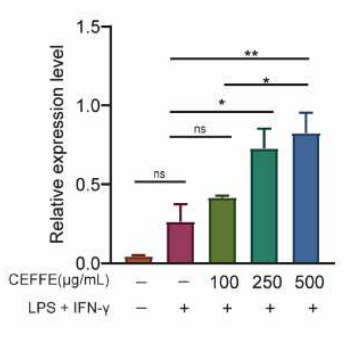

SOD-2

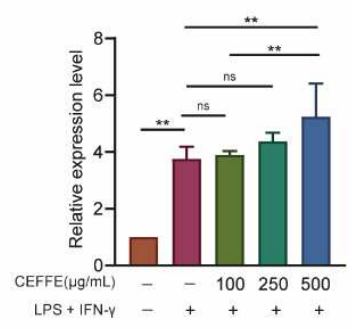

Fig. 7 CEFFE promoted the expression of antioxidant enzymes in Raw 264.7 cells. a, b Western blotting revealed an increase in the expression of antioxidant enzymes (GPX-1 and CAT) after co-incubation with CEFFE. c qRTPCR analysis showed that the expression of antioxidant enzymes (GPX-1, CAT, SOD-1, and SOD-2) was increased after co-incubation with CEFFE. ${ }^{*} \mathrm{p}<0.05$; ${ }^{* *} \mathrm{p}<0.01$; ns, no significant difference between groups.

We also found that the fluorescence intensity declined in murine primary chondrocytes treated with $250 \mu \mathrm{g} / \mathrm{mL}$ CEFFE; in particular, CEFFE reduced the inflammation-induced fluorescence intensity of primary chondrocytes (Fig. 8a, b, c). We also detected the expression of COX-2 and iNOS using qPCR and western blotting. CEFFE reduced the expression of both inflammation-activated COX-2 and iNOS (Fig. 8d, e, f, g, h). 
a

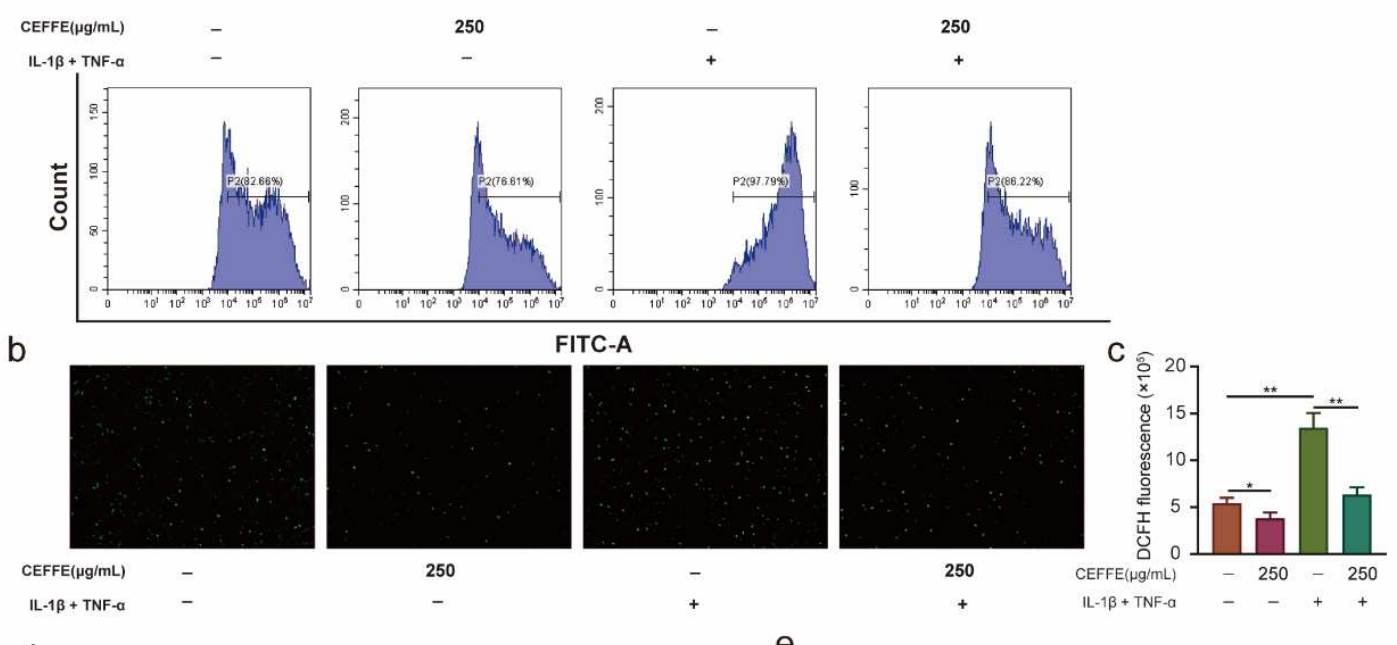

d

cox-2

e inos
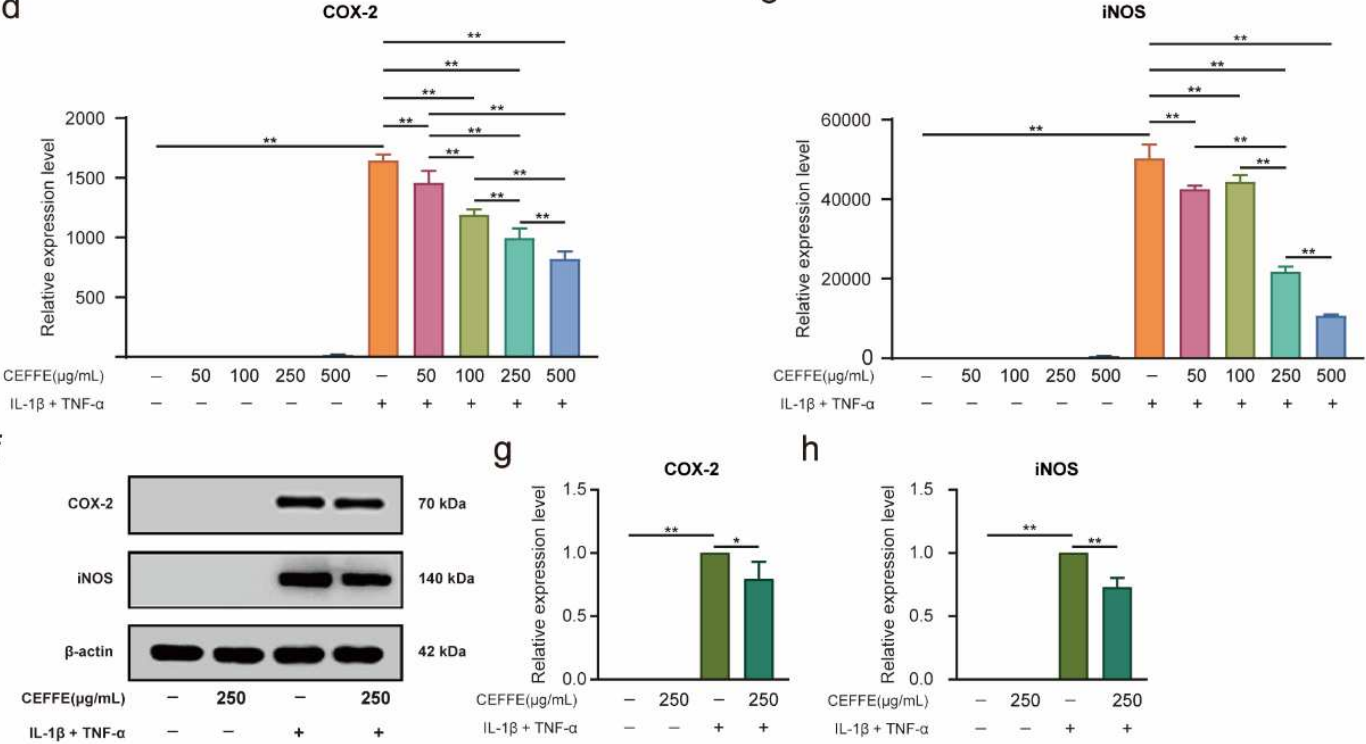

$\mathrm{h}$

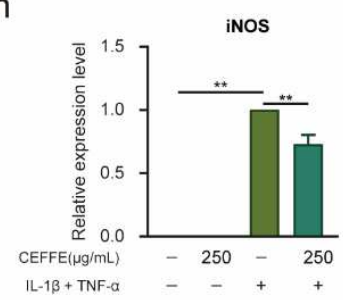

Fig. 8 CEFFE reduced the intracellular production of ROS and expression of oxidative stress-related enzymes in murine primary chondrocytes. a Flow cytometry analysis revealed that CEFFE counteracted the intracellular production of ROS induced by IL-1 $\beta+$ TNF- $\alpha$. b, $\mathbf{c}$ Fluorescence microscopy observation of DCHF fluorescence intensity showed a similar trend to that of flow cytometry. d, e qRT-PCR analysis showed that CEFFE did not affect the expression of oxidative stress-related enzymes (COX-2 and iNOS) in the absence of IL-1 $\beta+$ TNF- $\alpha$ but decreased their IL- $1 \beta+$ TNF- $\alpha$-induced expression in a dose-depend manner. $\mathbf{f}, \mathbf{g}$, and $\mathbf{h}$ qRT-PCR analysis showed that CEFFE had no effect on the expression of oxidative stress-related enzymes (COX-2 and iNOS) in the absence of IL- $1 \beta+$ TNF- $\alpha$, but decreased their IL- $1 \beta+$ TNF- $\alpha$-induced expression. ${ }^{*} \mathrm{p}<0.05 ;{ }^{* *} \mathrm{p}<0.01$; ns, no significant difference between groups.

\section{Discussion}

At present, the clinical treatment of $\mathrm{OA}$ includes mainly non-pharmacological treatments through mechanical stimulation and symptomatic treatments, which mainly focus on pain management and do not facilitate the regeneration of cartilage or reduce joint inflammation [7, 18]. These limitations require the development of novel, simple, efficient, and sound 
therapeutic approaches. Many clinical trials or extensive animal experiments have reported that stem cells represent a valid candidate for the cure of OA due to their capacity to differentiate and their ability to produce paracrine growth factors, such as TGF- $\beta 1$ and VEGF [23-26, 44, 45]. Moreover, some studies have demonstrated that an innovative cell-free strategy is equivalent to stem cell therapy, avoiding the disadvantages and ethical concerns associated with the use of stem cells [46]. In the current study, we demonstrated that CEFFE, which contained cytokines similar to those produced by stem cells could promote cartilage regeneration and alleviate low-grade inflammation in an MIA-induced OA rat model. In addition, we explored the underlying mechanisms and confirmed the therapeutic effects of CEFFE in Raw 264.7 macrophages and murine primary chondrocytes.

It has been shown that inflammatory changes, especially the polarized phenotype of macrophages in OA synovium, correlate with the pathogenesis and progression of OA [47]. Stem cells, exosomes, and platelet-rich plasma (PRP) therapies can shift pro-inflammatory M1 into anti-inflammatory M2 macrophages by immunomodulatory bioactive factors through a series of complex mechanisms [48-50]. Our previous studies showed that CEFFE regulated inflammation by reducing the infiltration of macrophages in the skin [35]. In the current study, we confirmed the effectiveness of CEFFE in regulating macrophages both in vivo and in vitro. Using in vivo experiments, we found that CEFFE increased the proportion of anti-inflammatory M2 macrophages in the synovium, while through in vitro experiments, we found that CEFFE mediated inflammation by inhibiting the M0 to M1 polarization of macrophages. Concomitantly, we found that CEFFE reduced the expression of the IL-1 $\beta$, IL-6, iNOS, and TNF- $\alpha$ pro-inflammatory factors, but increased the expression of the ARG and IL-10 antiinflammatory factors. We speculated that multiple growth factors such as TFG- $\beta$ and IGF-1in CEEFE might be responsible for the anti-inflammatory effects [31]. For instance, TGF- $\beta$ might inhibit natural killer lymphocytes and the maturation of inflammatory macrophages [46]. IGF1 might inhibit the activation of NF- $\mathrm{kB}$ and its downstream targets involved in inflammation, while hepatocyte growth factor might also reduce NF- $\kappa B$ signaling [51]. Therefore, we assumed that multiple components in CEFFE potentially function either independently or cooperatively [51].

The increased levels of ROS, which lead to elevated oxidative stress and direct damage to DNA, lipids, and proteins, also play an important role in the development of OA [52-54]. Furthermore, ROS also plays essential signaling functions in pathways including MAPKs and the NF- $\mathrm{BB}$ pro-inflammatory transcription factor, resulting in the increased expression of inflammatory cytokines, such as TNF- $\alpha$, IL-1 $\beta$, IL-6, and NO $[55,56]$. Accumulating evidence suggests that the elimination of excess ROS facilitates cartilage reconstruction and OA recovery [57]. Our previous studies have suggested that CEFFE increases the expression of antioxidant enzymes in fibroblasts, showing characteristics of an antioxidant agent [34]. In this study, we 
confirmed the antioxidant stress ability of CEFFE in the macrophage and chondrocyte models in vitro. In RAW264.7 cells, CEFFE mainly reduced ROS by increasing the expression of antioxidant stress kinases, whereas, in chondrocytes, CEFFE exerted its effect by reducing the expression of antioxidant stress kinases.

Another essential feature of $\mathrm{OA}$ is cartilage destruction under the inflammatory state. Type II collagen is the main protein component of cartilage, forming a mesh-like structure to embed aggrecan and other proteoglycans $[9,58,59]$. Long-term cartilage degradation leads to the activation of chondrocytes, which is characterized by the production of inflammatory cytokines, such as IL-1 $\beta$, TNF- $\alpha$, and matrix-degrading enzymes including the metalloproteinase (MMP) and ADAMTs-5 [60]. Research focusing on stem cells and their derivatives for cartilage regeneration and reduction in the levels of ADAMTs- 5 has shown promising results. Our previous studies indicated that CEFFE contains multiple growth factors that promote the proliferation and regeneration of fibroblasts and epidermal cells [32, 33]. The current study confirmed the ability of CEFFE to directly promote cartilage regeneration and reduce the level of matrix metalloproteinase and inflammatory mediators in vitro and vivo. Among those cytokines, TGF- $\beta$ might be a crucial factor stimulating cartilage regeneration, as it promotes the expression of SOX-9 and type II collagen [46].

Our data revealed the promising function of CEFFE in promoting cartilage repair and attenuating inflammatory states during the progression of OA. Compared with stem cell or PRP therapies, CEFFE possesses several advantages, such as non-immunogenicity and nontumorigenicity, which could overcome allograft-related problems, including the immune response and infection. In addition, CEFFE can be easily obtained in large quantities from liposuction waste or would only require one surgery and can be conveniently stored at $-80^{\circ} \mathrm{C}$. Compared with autologous PRP, CEFFE can be used from not only autologous sources but also allogeneic ones, potentially generating more consistent therapeutic effects and thus being more suitable for patients with OA requiring long-term treatment. These characteristics provided a theoretical basis for the future clinical application of CEFFE. A prospective study targeting autologous CEFFE in the treatment of knee OA is currently underway (Registration number: ChiCTR2100051039). However, as the specific components of CEFFE remain incompletely defined, future investigation on quality control of CEFFE from different donors or different batches is required. In the future, the use of purified functional proteins from CEFFE mixtures might take a more prominent role in treating OA.

In summary, by combining its excellent immunomodulation properties in regulating macrophage polarization and eliminating excess oxidative stress and cartilage protective effects, CEFFE appears to have promising therapeutic potential in OA.

\section{Conclusion}


In conclusion, our results demonstrated that CEFFE could be used as a promising strategy to inhibit or delay the progression of early-stage OA by promoting cartilage regeneration and limiting low-grade joint inflammation.

\section{Supplementary Information}

Figure S1. CEFFE did not show any effect on Raw 264.7 cells polarization without LPS + IFN$\gamma$. a, $\mathbf{c}$ Quantification of CD86-positive cells by flow cytometry. No obvious change in the proportion of M1 macrophages was observed after treatment with CEFFE. b, d Quantification of CD206 positive cells by flow cytometry. No obvious change was observed in the ratio of M2 cells. Data represent the mean \pm standard deviation ( $\mathrm{n}=3$ per group). ns, no significant difference between groups. Table S1. Gene primers used in the article.

\section{List of abbreviation}

ADAMTs-5: A disintegrin metalloproteinase with thrombospondin motifs 5; ADSCs: Adiposederived stem cells; ARG: Arginase; CAT: Catalases; CD206: Mannose receptor; CEFFE: Cellfree fat extract; DCFH-DA: 2, 7-Dichlorodihydrofluorescein diacetate; DMEM: Dulbecco's modified Eagle medium; FBS: Fetal bovine serum; GAG: Glycosaminoglycan; GPX: Glutathione peroxidase; HE: Hematoxylin-eosin; IFN: Interferon; IGF: Insulin-like factor; IL: Interleukin; iNOS: Inducible nitric oxide synthase; LPS: Lipopolysaccharide; MIA: Sodium iodoacetate; MMP: Metalloproteinase; MSCs: Mesenchymal stem cells; OA: Osteoarthritis; OARSI: Osteoarthritis Research Society International; PBS: Phosphate-buffered saline; qRTPCR: Quantitative real-time polymerase chain reaction; ROS: Reactive oxygen species; S\&F: Safranin O-fast green; SD: Sprague-Dawley; SOD: Superoxide dismutase; TGF: Transforming growth factor; TNF: Tumor necrosis factor; VEGF: Vascular endothelial growth factor

\section{Acknowledgments}

We would like to thank all of the Shanghai Key Laboratory of Tissue Engineering members for their discussions and help with this study. We would like to thank Editage (www.editage.cn) for English language editing.

\section{Authors' contributions}

The study was designed by ZY, WL and WZ. ZJ and BK contributed to experimentation, data collection, data analyses, manuscript writing and editing. YC and CC carried out some of experiments. All authors read and approved the final manuscript. 


\section{Funding}

This study was supported by the Shanghai Collaborative Innovation Program on Regenerative Medicine and Stem Cell Research (2019CXJQ01). The funder had no role in data collection, data management, data analysis, decision to publish, or manuscript preparation.

\section{Availability of data and materials}

The datasets during the current study are available from the corresponding author on reasonable request.

\section{Ethics approval and consent to participate}

The study was approved by the Ethics Committee of Shanghai Jiao Tong University School of Medicine, Shanghai, China.

\section{Consent for publication}

Not applicable

\section{Competing interests}

The author declare that they have no conflict of interest

\section{References}

1. Steinberg J, Southam L, Roumeliotis TI, Clark MJ, Jayasuriya RL, Swift D, et al. A molecular quantitative trait locus map for osteoarthritis. Nat Commun. 2021;12(1):1309.

2. Klein JC, Keith A, Rice SJ, Shepherd C, Agarwal V, Loughlin J, et al. Functional testing of thousands of osteoarthritis-associated variants for regulatory activity. Nat Commun. 2019;10(1):2434.

3. Shi Y, Hu X, Cheng J, Zhang X, Zhao F, Shi W, et al. A small molecule promotes cartilage extracellular matrix generation and inhibits osteoarthritis development. Nat Commun. 2019;10(1):1914.

4. Mang T, Lindemann S, Gigout A. Increasing the Medium Osmolarity Reduces the Inflammatory Status of Human OA Chondrocytes and Increases Their Responsiveness to GDF-5. Int J Mol Sci. 2020;21(2).

5. Deng Z, Jia Y, Liu H, He M, Yang Y, Xiao W, et al. RhoA/ROCK pathway: implication in osteoarthritis and therapeutic targets. Am J Transl Res. 2019;11(9):5324-31.

6. Sharma L. Osteoarthritis of the Knee. N Engl J Med. 2021;384(1):51-9.

7. Fernandes TL, Gomoll AH, Lattermann C, Hernandez AJ, Bueno DF, Amano MT. Macrophage: A Potential Target on Cartilage Regeneration. Front Immunol. 2020;11:111.

8. Rahmati M, Mobasheri A, Mozafari M. Inflammatory mediators in osteoarthritis: A critical review of the state-of-the-art, current prospects, and future challenges. Bone. 2016;85:81-90. 
9. Glyn-Jones S, Palmer AJ, Agricola R, Price AJ, Vincent TL, Weinans H, et al. Osteoarthritis. Lancet. 2015;386(9991):376-87.

10. Wu H, Hu B, Zhou X, Zhou C, Meng J, Yang Y, et al. Artemether attenuates LPS-induced inflammatory bone loss by inhibiting osteoclastogenesis and bone resorption via suppression of MAPK signaling pathway. Cell Death Dis. 2018;9(5):498.

11. Griffin TM, Scanzello CR. Innate inflammation and synovial macrophages in osteoarthritis pathophysiology. Clin Exp Rheumatol. 2019;37(5):57-63.

12. Musumeci G, Castrogiovanni P, Trovato FM, Weinberg AM, Al-Wasiyah MK, Alqahtani MH, et al. Biomarkers of Chondrocyte Apoptosis and Autophagy in Osteoarthritis. Int J Mol Sci. 2015;16(9):20560-75.

13. O'Brien K, Tailor P, Leonard C, DiFrancesco LM, Hart DA, Matyas JR, et al. Enumeration and Localization of Mesenchymal Progenitor Cells and Macrophages in Synovium from Normal Individuals and Patients with Pre-Osteoarthritis or Clinically Diagnosed Osteoarthritis. Int J Mol Sci. 2017;18(4).

14. Dai M, Sui B, Xue Y, Liu X, Sun J. Cartilage repair in degenerative osteoarthritis mediated by squid type II collagen via immunomodulating activation of M2 macrophages, inhibiting apoptosis and hypertrophy of chondrocytes. Biomaterials. 2018;180:91-103.

15. Sica A, Mantovani A. Macrophage plasticity and polarization: in vivo veritas. J Clin Invest. 2012;122(3):787-95.

16. Mantovani A, Biswas SK, Galdiero MR, Sica A, Locati M. Macrophage plasticity and polarization in tissue repair and remodelling. J Pathol. 2013;229(2):176-85.

17. Chen Z, Zhong H, Wei J, Lin S, Zong Z, Gong F, et al. Inhibition of Nrf2/HO-1 signaling leads to increased activation of the NLRP3 inflammasome in osteoarthritis. Arthritis Res Ther. 2019;21(1):300.

18. Ansari MY, Ahmad N, Haqqi TM. Oxidative stress and inflammation in osteoarthritis pathogenesis: Role of polyphenols. Biomed Pharmacother. 2020;129:110452.

19. Yao H, Xu J, Wang J, Zhang Y, Zheng N, Yue J, et al. Combination of magnesium ions and vitamin $\mathrm{C}$ alleviates synovitis and osteophyte formation in osteoarthritis of mice. Bioact Mater. 2021;6(5):1341-52.

20. Xie J, Lin J, Wei M, Teng Y, He Q, Yang G, et al. Sustained Akt signaling in articular chondrocytes causes osteoarthritis via oxidative stress-induced senescence in mice. Bone Res. 2019;7:23.

21. Yang R, Chen F, Guo J, Zhou D, Luan S. Recent advances in polymeric biomaterials-based gene delivery for cartilage repair. Bioact Mater. 2020;5(4):990-1003.

22. Freitag J, Bates D, Wickham J, Shah K, Huguenin L, Tenen A, et al. Adipose-derived mesenchymal stem cell therapy in the treatment of knee osteoarthritis: a randomized controlled trial. Regen Med. 2019;14(3):213-30.

23. He L, He T, Xing J, Zhou Q, Fan L, Liu C, et al. Bone marrow mesenchymal stem cell-derived exosomes protect cartilage damage and relieve knee osteoarthritis pain in a rat model of osteoarthritis. Stem Cell Res Ther. 2020;11(1):276. 
24. Lamo-Espinosa JM, Blanco JF, Sanchez M, Moreno V, Granero-Molto F, Sanchez-Guijo F, et al. Phase II multicenter randomized controlled clinical trial on the efficacy of intra-articular injection of autologous bone marrow mesenchymal stem cells with platelet rich plasma for the treatment of knee osteoarthritis. J Transl Med. 2020;18(1):356.

25. Lee WS, Kim HJ, Kim KI, Kim GB, Jin W. Intra-Articular Injection of Autologous Adipose Tissue-Derived Mesenchymal Stem Cells for the Treatment of Knee Osteoarthritis: A Phase IIb, Randomized, Placebo-Controlled Clinical Trial. Stem Cells Transl Med. 2019;8(6):504-11.

26. Murphy JM, Fink DJ, Hunziker EB, Barry FP. Stem cell therapy in a caprine model of osteoarthritis. Arthritis Rheum. 2003;48(12):3464-74.

27. Rochette L, Mazini L, Malka G, Zeller M, Cottin Y, Vergely C. The Crosstalk of AdiposeDerived Stem Cells (ADSC), Oxidative Stress, and Inflammation in Protective and Adaptive Responses. Int J Mol Sci. 2020;21(23).

28. Ahlfors JE, Azimi A, El-Ayoubi R, Velumian A, Vonderwalde I, Boscher C, et al. Examining the fundamental biology of a novel population of directly reprogrammed human neural precursor cells. Stem Cell Res Ther. 2019;10(1):166.

29. Clark K, Zhang S, Barthe S, Kumar P, Pivetti C, Kreutzberg N, et al. Placental Mesenchymal Stem Cell-Derived Extracellular Vesicles Promote Myelin Regeneration in an Animal Model of Multiple Sclerosis. Cells. 2019;8(12).

30. Haertinger M, Weiss T, Mann A, Tabi A, Brandel V, Radtke C. Adipose Stem Cell-Derived Extracellular Vesicles Induce Proliferation of Schwann Cells via Internalization. Cells. 2020;9(1).

31. Yu Z, Cai Y, Deng M, Li D, Wang X, Zheng H, et al. Fat extract promotes angiogenesis in a murine model of limb ischemia: a novel cell-free therapeutic strategy. Stem Cell Res Ther. 2018;9(1):294.

32. Cai Y, Yu Z, Yu Q, Zheng H, Xu Y, Deng M, et al. Fat Extract Improves Random Pattern Skin Flap Survival in a Rat Model. Aesthet Surg J. 2019;39(12):NP504-NP14.

33. Deng M, Wang X, Yu Z, Cai Y, Liu W, Zhou G, et al. Cell-free fat extract promotes tissue regeneration in a tissue expansion model. Stem Cell Res Ther. 2020;11(1):50.

34. Deng M, Xu Y, Yu Z, Wang X, Cai Y, Zheng H, et al. Protective Effect of Fat Extract on UVBInduced Photoaging In Vitro and In Vivo. Oxid Med Cell Longev. 2019;2019:6146942.

35. Wang X, Deng M, Yu Z, Cai Y, Liu W, Zhou G, et al. Cell-free fat extract accelerates diabetic wound healing in db/db mice. Am J Transl Res. 2020;12(8):4216-27.

36. Xu Y, Deng M, Cai Y, Zheng H, Wang X, Yu Z, et al. Cell-Free Fat Extract Increases Dermal Thickness by Enhancing Angiogenesis and Extracellular Matrix Production in Nude Mice. Aesthet Surg J. 2020;40(8):904-13.

37. Zheng H, Yu Z, Deng M, Cai Y, Wang X, Xu Y, et al. Fat extract improves fat graft survival via proangiogenic, anti-apoptotic and pro-proliferative activities. Stem Cell Res Ther. 2019;10(1):174.

38. Kang B, Cai Y, Jia Z, Chen C, Deng M, Zhang W, et al. Cell-Free Fat Extract Prevents Vaginal Atrophy in an Ovariectomized Model by Promoting Proliferation of Vaginal Keratinocytes and Neovascularization. Aesthet Surg J. 2022;42(1):NP55-NP68. 
39. Ji Q, Xu X, Kang L, Xu Y, Xiao J, Goodman SB, et al. Hematopoietic PBX-interacting protein mediates cartilage degeneration during the pathogenesis of osteoarthritis. Nat Commun. 2019;10(1):313.

40. Gemei M, Talarico C, Brandolini L, Manelfi C, Za L, Bovolenta S, et al. Binding Mode Exploration of B1 Receptor Antagonists' by the Use of Molecular Dynamics and Docking Simulation-How Different Target Engagement Can Determine Different Biological Effects. International Journal of Molecular Sciences. 2020;21(20).

41. Pritzker KP, Gay S, Jimenez SA, Ostergaard K, Pelletier JP, Revell PA, et al. Osteoarthritis cartilage histopathology: grading and staging. Osteoarthritis Cartilage. 2006;14(1):13-29.

42. Deng H, Li Z, Tan Y, Guo Z, Liu Y, Wang Y, et al. A novel strain of Bacteroides fragilis enhances phagocytosis and polarises M1 macrophages. Sci Rep. 2016;6:29401.

43. Livak KJ, Schmittgen TD. Analysis of relative gene expression data using real-time quantitative PCR and the 2(-Delta Delta C(T)) Method. Methods. 2001;25(4):402-8.

44. Desando G, Cavallo C, Sartoni F, Martini L, Parrilli A, Veronesi F, et al. Intra-articular delivery of adipose derived stromal cells attenuates osteoarthritis progression in an experimental rabbit model. Arthritis Res Ther. 2013;15(1):R22.

45. Tran C, Damaser MS. Stem cells as drug delivery methods: application of stem cell secretome for regeneration. Adv Drug Deliv Rev. 2015;82-83:1-11.

46. Zavatti M, Beretti F, Casciaro F, Bertucci E, Maraldi T. Comparison of the therapeutic effect of amniotic fluid stem cells and their exosomes on monoiodoacetate-induced animal model of osteoarthritis. Biofactors. 2020;46(1):106-17.

47. Caric D, Zekic Tomas S, Filipovic N, Soljic V, Benzon B, Glumac S, et al. Expression Pattern of iNOS, BCL-2 and MMP-9 in the Hip Synovium Tissue of Patients with Osteoarthritis. Int J Mol Sci. 2021;22(3).

48. Ye G, Xie Z, Zeng H, Wang P, Li J, Zheng G, et al. Oxidative stress-mediated mitochondrial dysfunction facilitates mesenchymal stem cell senescence in ankylosing spondylitis. Cell Death Dis. 2020;11(9):775.

49. Wang R, Xu B. TGF-beta1-modified MSC-derived exosomal miR-135b attenuates cartilage injury via promoting M2 synovial macrophage polarization by targeting MAPK6. Cell Tissue Res. 2021;384(1):113-27.

50. Uchiyama R, Toyoda E, Maehara M, Wasai S, Omura H, Watanabe M, et al. Effect of PlateletRich Plasma on M1/M2 Macrophage Polarization. Int J Mol Sci. 2021;22(5).

51. Ti D, Hao H, Tong C, Liu J, Dong L, Zheng J, et al. LPS-preconditioned mesenchymal stromal cells modify macrophage polarization for resolution of chronic inflammation via exosomeshuttled let-7b. J Transl Med. 2015;13:308.

52. Arra M, Swarnkar G, Ke K, Otero JE, Ying J, Duan X, et al. LDHA-mediated ROS generation in chondrocytes is a potential therapeutic target for osteoarthritis. Nat Commun. 2020;11(1):3427.

53. Drevet S, Gavazzi G, Grange L, Dupuy C, Lardy B. Reactive oxygen species and NADPH oxidase 4 involvement in osteoarthritis. Exp Gerontol. 2018;111:107-17.

54. Zhong G, Yang X, Jiang X, Kumar A, Long H, Xie J, et al. Dopamine-melanin nanoparticles 
scavenge reactive oxygen and nitrogen species and activate autophagy for osteoarthritis therapy. Nanoscale. 2019;11(24):11605-16.

55. Pei Y, Cui F, Du X, Shang G, Xiao W, Yang X, et al. Antioxidative nanofullerol inhibits macrophage activation and development of osteoarthritis in rats. Int J Nanomedicine. 2019;14:4145-55.

56. Hwang KA, Kwon JE, Noh Y, Park B, Jeong YJ, Lee SM, et al. Effects of Zanthoxylum piperitum ethanol extract on osteoarthritis inflammation and pain. Biomed Pharmacother. 2018;105:481-90.

57. Sellam J, Berenbaum F. The role of synovitis in pathophysiology and clinical symptoms of osteoarthritis. Nat Rev Rheumatol. 2010;6(11):625-35.

58. Park JS, Yang HN, Woo DG, Jeon SY, Park KH. Chondrogenesis of human mesenchymal stem cells in fibrin constructs evaluated in vitro and in nude mouse and rabbit defects models. Biomaterials. 2011;32(6):1495-507.

59. You M, Peng G, Li J, Ma P, Wang Z, Shu W, et al. Chondrogenic differentiation of human bone marrow mesenchymal stem cells on polyhydroxyalkanoate (PHA) scaffolds coated with PHA granule binding protein PhaP fused with RGD peptide. Biomaterials. 2011;32(9):2305-13 .

60. Cui Z, Crane J, Xie H, Jin X, Zhen G, Li C, et al. Halofuginone attenuates osteoarthritis by inhibition of TGF-beta activity and H-type vessel formation in subchondral bone. Ann Rheum Dis. 2016;75(9):1714-21. 


\section{Supplementary Files}

This is a list of supplementary files associated with this preprint. Click to download.

- GraphicAbstract.tif

- Figures1.docx

- Tables1.docx 